$\xi=-1$

\title{
Study of E-mail Data Services based on Delay Tolerant Network in The Riau Province Border Region
}

\author{
Oktaf B. Kharisma ${ }^{1}$, Folkes E. Laumal ${ }^{2}$, Triawan A. Cahyanto ${ }^{3}$, Dwi Ermayanti Susilo ${ }^{4}$, Petrisia W. Sudarmadji ${ }^{5}$ \\ ${ }^{I}$ Electrical Engineering, Faculty of Science and Technology, UIN Sultan Syarif Kasim Riau \\ ${ }_{2,5}$ Politeknik Negeri Kupang. \\ ${ }^{3}$ University of Muhammadiyah Jember \\ ${ }^{4}$ STIE PGRI Dewantara Jombang \\ *Corresponding author E-mail: brilliankhar@gmail.com
}

\begin{abstract}
Indonesia is an archipelagic country that is geographically unique, where most of the land has uneven land contours because it consists of mountains and valleys. This condition is one of the causes of the inequality of information dissemination even though the ICT infrastructure has supported and internet services are also available. Topographical factors and inequality of information dissemination pose digital deviations in the community, especially border areas in Riau Province which have not been able to enjoy internet services in some of the regions. Even though the process of data transmission to other regions is needed by both government agencies placed in border areas and the general public who need internet services for data transmission (text, audio, and video). Delay Tolerant Network (DTN) technology is a network protocol that allows communication networks to be applied in extreme environments that have long delay characteristics, high loss rates, and low connectivity levels. With DTN, internet services can be implemented and presented cheaply using only DTN Router which will move to areas that are not reachable by the internet and collect email data digitally. Furthermore, DTN Router and processes every transmission request from/to the border regions with extreme topography. By using the Flooding method applied to the DTN protocol, testing of e-mail data packet transmission from simulations at several locations in Riau is considered to have high data loss. Testing modeled by several computers with DTN, doing a bundle of data packages, transmitting to destinations and assessing the efficiency of their success. The test results show that the data transmission process in extreme areas using DTN protocol, Indicates that the larger the size of the file sent. So, the greater the time needed for data transmission. Approximate of time is needed of transmission data of the $95 \mathrm{MB}$ file that is 4,1 second..
\end{abstract}

Keywords: Delay Tolerant Network; bundle; e-bundle; flooding.

\section{Introduction}

Today, internet communication is integrated into all life activities and becomes a primary need that cannot be avoided. The emergence of the internet technology raises people's habits from the use of conventional media to be automatic, smart and digitally based in text data transmission, audio and video based on standalone and client-server [1] [2]. Automatic and digital systems are developed because they are faster and more accurate, such as email services.

E-mail is one application for sending electronic mail (online) by replacing the existing postal system. First of the development of the internet, there were millions of e-mail users in the world (even growing) who only spent their time/study using e-mail services [3]. In his research shows that email has contributed to the growth of distributed organizations, by allowing people in various regions to be able to communicate [4][5]. This also led to the emergence of an online community that supports asynchronous communication.

The original email application was designed for asynchronous communication, document delivery and archiving only. However, it is development, delegation and tracking tasks, storing personal names and addresses, sending reminders, requesting assistance, scheduling appointments and handling other technical support requests, giving rise to data overload (overload email uncontrolled) [6][7].

On the other hand, Indonesia is an archipelagic country that is geographically part of the land dominated by hills, valleys, and mountains so that information dissemination is not optimal and uneven despite utilizing satellite technology with a good real-time data queue mechanism [8]. Internet technology that has grown to all parts of Indonesia, in the end, has not guaranteed internet communication will be good in all parts of Indonesia. The existing trend is even the occurrence of digital sharing in the community, especially in remote areas of the border, for example, the border area in Riau Province which has not been able to enjoy internet services.

According to the 2010 Indonesian Ministry of Communication and Information statistics, in June 2009, there were still 31 thousand villages in Indonesia that were not affordable with internet technology. Meanwhile, after 7 years later (in 2016) based on data from the same source, Indonesia, which consists of 17,504 islands, only about $2 \%$ were recorded as getting internet services[9][10]. Delay Tolerant Network (DTN) is a network protocol that is able to present communication in an environment with characteristics delay varying, asymmetric data rates error rates, high, and frequent interconnections (on-off-on-off)[11][12]. DTN technology is different from the previous working protocol concept, TCP/IP which relies on upon continuing connectivity or every sent file 
will be lost when the connection is lost. DTN is suitable for use in extreme areas (black hole) so the concept of Delay Tolerant Network (DTN) is a solution for border areas and can be applied by utilizing mobile vehicles that act as DTN router [13] [14] [15] The router will collect every file that will be transmitted and when it gets a location that has TCP/IP protocol internet access, the Router will distribute the collected data to be transmitted. The movement of DTN Router from one node to another node is continuous following the concept of flooding algorithm [16].

DTN applies the store and forwards message switching method to a new layer called the layer bundle. The layer bundle will save and forward the entire bundle and or just a fragment between the nodes that communicate with the DTN [17] [18]. Illustration of the store and the forward mechanism is shown in Figure 1.

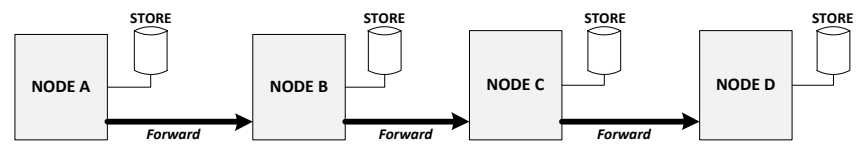

Figure 1: Illustration of mechanism store-and-forward in DTN

As shown in Figure 1, Store and forward are old methods similar to those used in postal networks. With the method store and forward, all data taken will be moved first from one node to another node until it finally reaches the destination. A node must have a hard disk that is used as a storage medium that can store the entire data [19]. So, it is possible that data can be on a node for a long time, in contrast to packets on the internet that will only be stored in a router in a matter of milliseconds or microseconds. A DTN router requires a storage area because the connected paths in each node may not be available for a long time, meaning that they have wide or long distances in their connectivity and the possibility of communication that cannot take place symmetrically [20].

This study simulates the movement of DTN Router in several points of the Riau Province border region and disseminates data (text) to other places where connections end-to-end are not available while providing alternative solutions for using the protocol Delay Tolerant Network for data transmission in remote areas that still have problems communication and frequent interruption of internet connection

\section{Methods}

The simulation about Routers collects and transmits data using the DTN protocol through 4 phases, namely: determining data service schemes that are the target of DTN implementation, preparation of data delivery applications, preparation of DTN networks and implementation. Each stage is explained as follows.

\subsection{Border Area}

Network service scheme the design of network service schemes as a target to the implementation of data transmission using the DTN protocol as given in Figure 2.

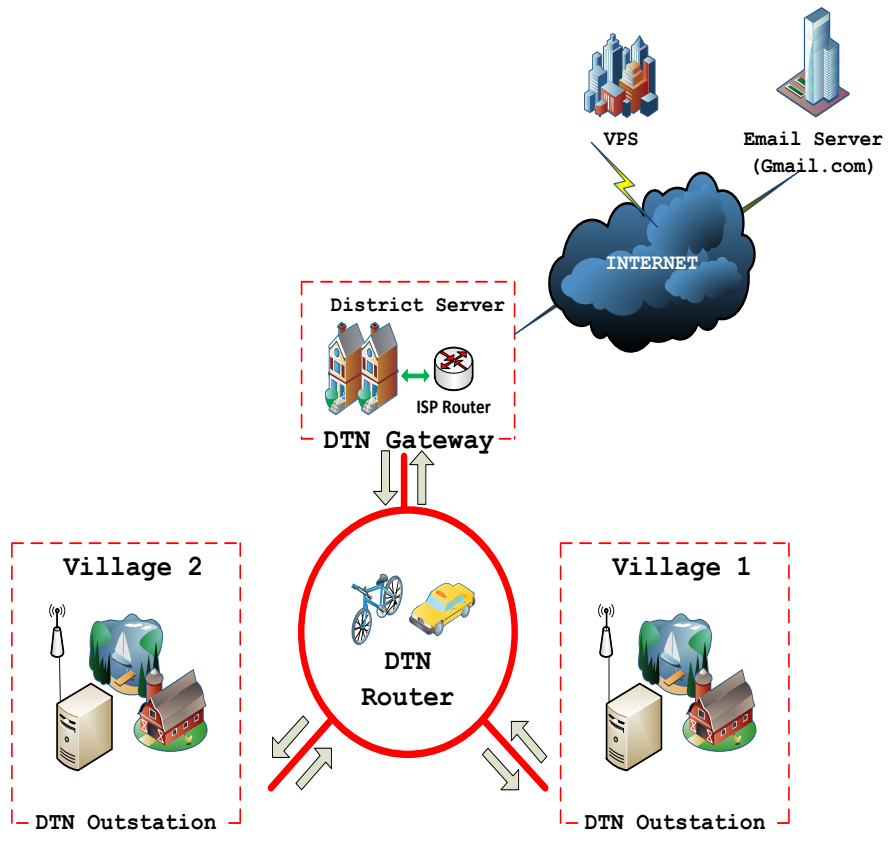

Figure 2: Email Network and Service System

Generally, speaking the network service system in Figure 2 that will be simulated is grouped into 3 parts, namely DTN gateway, DTN router (mule-DTN) and DTN outstation (remote area). DTN Gateway is a node that has connections to Internet Service Providers (ISPs) that connect DTN networks with the global internet. The connection between DTN Gateway and DTN outstation is done with a DTN Router in the form of a router that moves between DTN networks. The DTN Outstation is an access point to a remote area where all data files are will be sent or received through this node by DTN users. When DTN users in remote areas send data (i.e e-mail). Then, the data will be stored first in the DTN Outstation until the DTN Router is within its access point range. Then, it will retrieve and send it to the destination via the DTN gateway. When the data to be sent is available on the Outstation DTN. However, the DTN Router is not available; the data will be stored for sending or receiving the next day.

Assuming an area remote in Riau Province as an area in the middle of a forest or a valley area surrounded by mountains, the distance between other remote areas is assumed to be $\pm 10 \mathrm{~km}$ in a sub-district government area. The Main server will download every service email entered on the internet addressed by the user to the DTN Outstation. The results of download in a content email on internet services will be stored on the Virtual Private Server (VPS) as the main server of DTN which will then be downloaded by district server (DTN Gateway) via a public internet network that is connected to an ISP. The contents of the service email downloaded by the District server will be saved and will be disseminated using DTN Router by downloading and addressed to each server located in each remote area via a wifi (access point) connection.

When DTN Router moves past a location and is included in a network $\mathrm{Wi}-\mathrm{Fi}$ in the area, they will send data to the server that has been downloaded previously from the internet. At the same time, servers in remote areas will send data to DTN Router in the form of e-mails from remote area users that are addressed to other remote area users in one area or another.

If a remote area of destination has been exceeded or not exceeded by DTN Router, then the data email for the area will be forwarded and uploaded to the district server for further download by another DTN Router at different times data Email from users in remote areas that are addressed to users of services email on the Internet will be uploaded to District server to be forwarded and uploaded to the Server via District server via a public Internet network that 
is connected to an ISP. Email between users will be forwarded to the Internet network according to the destination.

\subsection{The compiler of Email Delivery Application based on DTN}

The composition of the application compiler in DTN-based email services is designed according to Figure 3 and explained as follows.

1. Gmail is an e-mail server application for e-mail services on the global internet that provides applications for receiving and sending. Users email connected to the global internet network will be received and collected by the main server in Virtual Private Machine (VPS) then grouped according to the destination area. The send-receive application on the VPS functions as a processing process for sending and receiving incoming data from Gmail or from the district server and will be sent to the destination. At the destination, the next data is then grouped and temporarily stored in bundle-mail.

2. District server (located in districts) in the DTN Gateway area is used as a temporary stop from the global internet network and the village DTN network before being distributed to destinations using DTN Router. District server includes a computer device as DTN Gateway connecting system with non-DTN and DTN network, receiving and sending mail application to process each email incoming and outgoing from DTN outstation using DTN protocols and methods SSH Tunnel.

3. DTN Router (i.e transportation) to forward data email between district servers to remote areas using DTN networks. It is will be automatically connected with DTN nodes using the access point network. Then periodically every time there is connectivity, it will take packages in the form of bundles that are in the District server or in remote villages.

4. DTN outstation as a remote area (i.e village) is a DTN network outstation in the form of a computing device as an e-mail server with an application to send and receive e-mail for village community services. Bundle-mail will be captured using send and receive applications that are built using the Python language and run on the system backend. For e-mail interface, services application is used client squirrel mail.

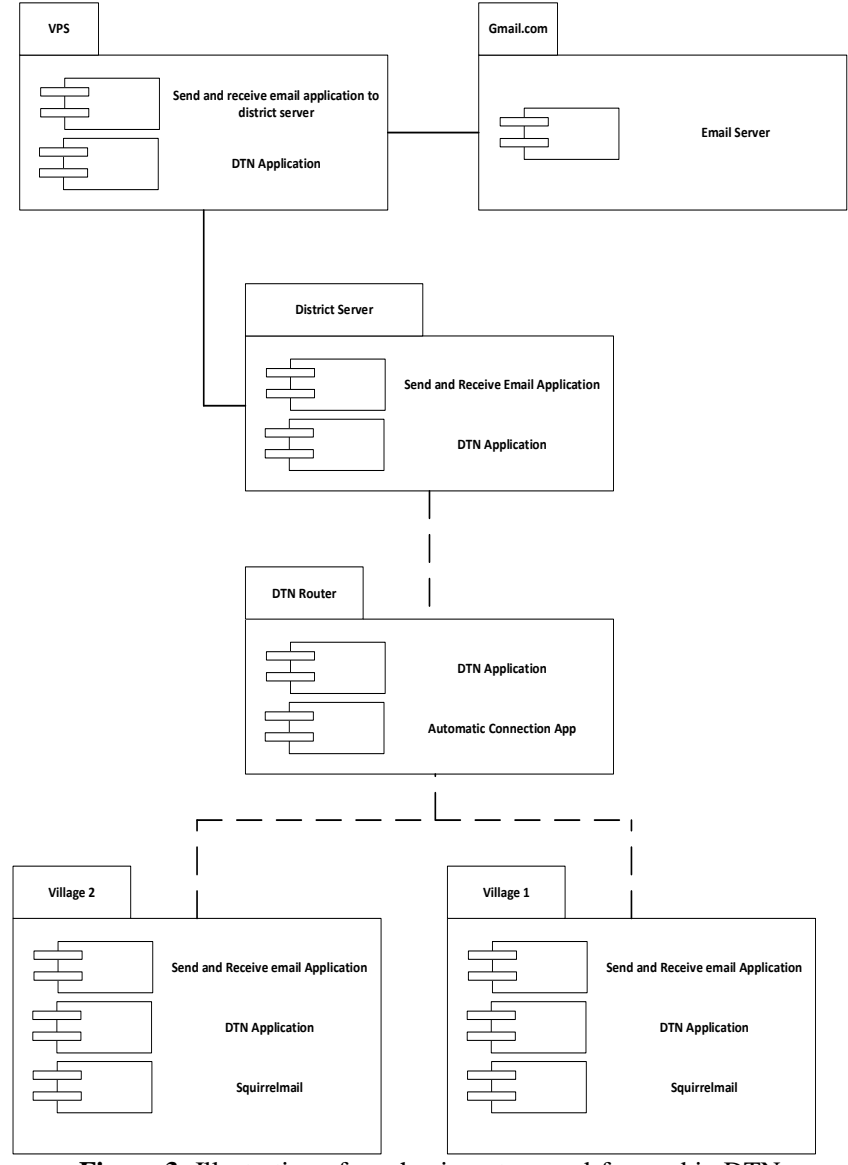

Figure 3: Illustration of mechanism store-and-forward in DTN

\subsection{Composition Delay Tolerant Network (DTN)}

The composition of DTN Network Compiler was designed in Figure 4 and explained follows.

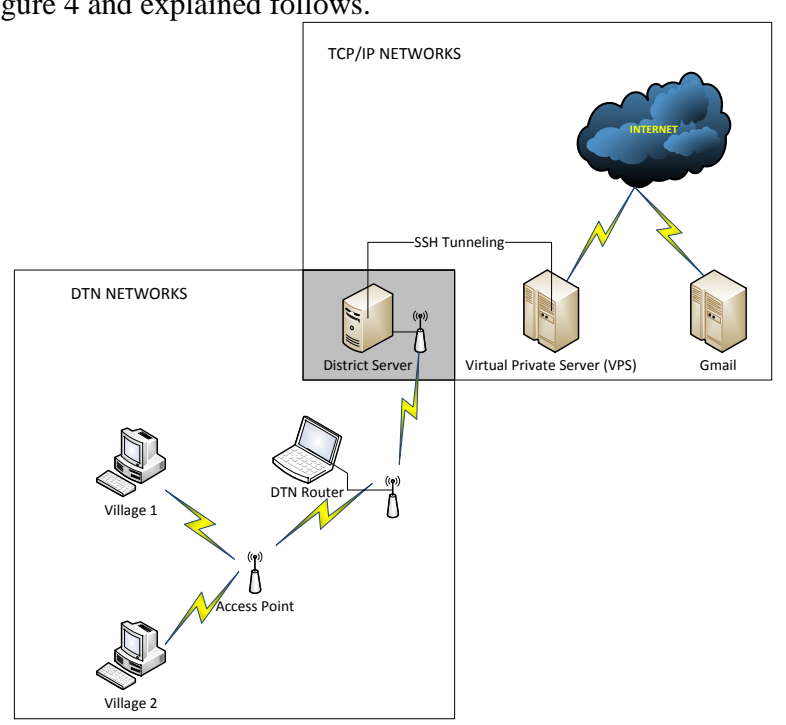

Figure 4 Composition of DTN Network for email Services

1. Gmail as a means of providing external email delivery applications for users outside the DTN network.

2. VPS (Virtual Private Server) as the Main server of DTN network which will provide e-mail services in the form of e-mail management that will be addressed in the DTN network or to the global internet in this case Gmail.

3. District server is gateways between systems that use non-DTN networks (TCP / IP) with systems with DTN networks. District server is equipped with a device Wireless Outdoor CPE which is set up as a Wi-Fi access point (Wi-Fi AP) to connect 
with DTN Router and HSDPA 3G modem devices to connect the District server computer to the VPS computer through the ISP network using the method SS tunneling.

4. DTN Router was built using the Odroid XU4 microcomputer, which functioned as a DTN router. For connection devices, DTN Router is equipped with a device Wireless Outdoor CPE which is set as a DHCP client.

5. Access Point (AP), serves to connect between computer servers in each village and DTN routers that pass through it.

Computer Servers in remote areas are a computer device for processing and managing e-mail for rural communities that are passed by DTN Router. For connections, the Village Computer is equipped with a device Wireless Outdoor CPE that is set up as a Wi-Fi AP to connect a Computer Server in a remote area with DTN Router and Users in remote areas.

\section{Result and Discussion}

\subsection{Implementation of System}

Implementation DTN-based data transmission simulation system is shown in Figure 5.

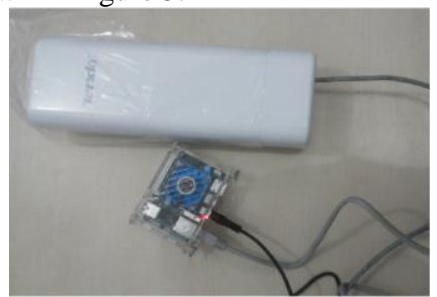

(a)

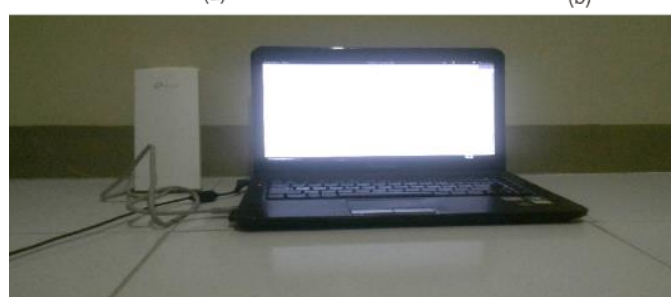

Figure 5 Composition of DTN Network for email Services

As in Figure 5, each DTN network node implemented with 3 computers. The delivery application is Email implemented using Python and PHP programming, Linux System Command in the form of programming bash shell that is run on the backend system and the email client application using Squirrel Mail. To make it easier for users to send and receive emails. The application is divided into two sections, namely first section that uses the DTN network and the other does not use the DTN network. For the process of e-mail transfers between nodes in the DTN network using DTN protocols and architectures that are applied with DTN2 software on each computer, namely computers District server, Odroid UX4 microcomputers and server computers in remote areas (DTN outstation). The DTN installed only runs on the Linux operating system. Meanwhile, to support the operation of DTN, applications dtn-2.9.0, Oasys-1.6.0 and other dependencies are used.

The implementation of the email sending process in each village begins with authentication logging in by the user based on the data on the village server. The authentication process will produce output as Figure 6.

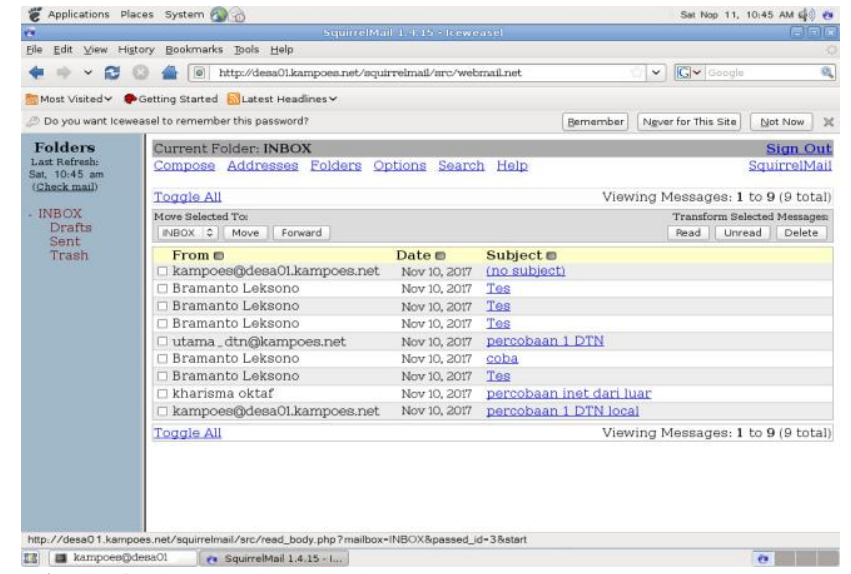

Figure 6: Display of the e-mail received on the server's remote location.

Figure 6 displays the status in the inbox directory of the server placed in the remote area with the stored e-mail document. The simulation shows that \pm 10 data taken on November 10 is stored in the directory and ready to be bundled to be sent to the destination. The bundling process is then given in Figure 7 and Figure 8.

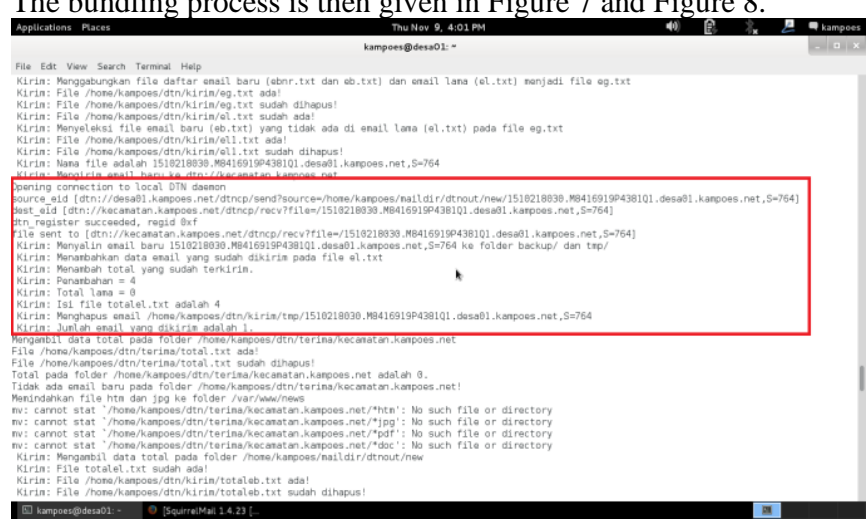

Figure 7: Python applications when processing email bundles.

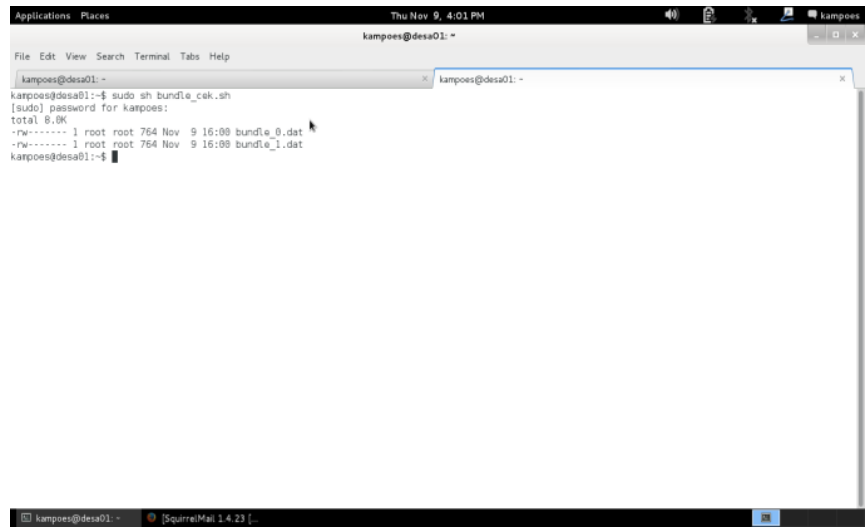

Figure 8: Bundled e-mail

Figure 7 shows the program snippet bundling data (e-mail) from a server in a remote area to be transmitted to the desired destination. Program protection also describes the copy process for all email data that is in the server's computer inbox directory and sends one by one serial data. Whereas in Figure 8 shows the transmission report that will be given to the user that the data bundle process (bundle-mail) is resolved in the root.

\subsection{Network Testing}

The testing of service email system dismissed using flooding method and described in Figure 9. 


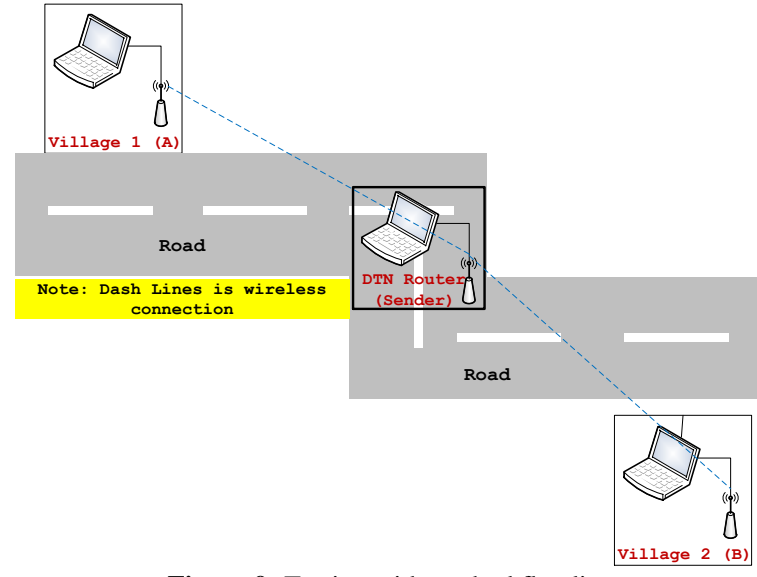

Figure 9: Testing with method flooding

Tests are carried out as in Figure 9, carried out by modeling several computers previously configured with DTN2 software. Tests are carried out to analyze the performance of DTN router in data transmission and the reliability of the sent e-mail package. DTN Router which functions as a carrier for packages bundle from this email is very important in data transmission. Thus, a deeper study is still needed to obtain the efficiency of using routers in service systems email that is in the networks based on DTN.

The test scenario is made using the method of flooding where the entity is the sender is DTN Router, the data is sent from node A to node $\mathrm{B}$, the sender is connected to network $\mathrm{A}$, the sender moves and changes the connection to network $\mathrm{B}$, the movement from node A to node B is done using a motorcycle with take the power supply from the battery, and the Sender's movement is carried out continuously through the access point at each node.

Testing of email delivery is sent several times by sending dummy emails automatically with different sizes ranging in size from $55 \mathrm{MB}-135 \mathrm{MB}$. The automatic delivery format is as follows:

[number of sent] $=$ total number of emails to be sent [duplication] = duplicate number of emails from each address listed in the file destination.txt [increment] = increase in file size of each e-mail [size_email] $=$ size of each email

The simulation results provide test data as shown in Table 1 below.

Table 1 Testing Emails

\begin{tabular}{|c|c|c|c|c|}
\hline \multirow{2}{*}{ Ukuran File (MB) } & \multicolumn{2}{|c|}{ Waktu transfer (detik) } & \multirow{2}{*}{ rata-rata } \\
\cline { 2 - 4 } & Test 1 & Test 2 & \multicolumn{1}{c|}{ Test 3 } & \\
\hline 55 & $0: 02: 16$ & $0: 02: 23$ & $0: 02: 19$ & $0: 02: 19$ \\
\hline 65 & $0: 02: 45$ & $0: 02: 54$ & $0: 02: 32$ & $0: 02: 44$ \\
\hline 75 & $0: 03: 27$ & $0: 03: 12$ & $0: 03: 18$ & $0: 03: 19$ \\
\hline 85 & $0: 03: 49$ & $0: 03: 28$ & $0: 03: 35$ & $0: 03: 37$ \\
\hline 95 & $0: 03: 58$ & $0: 03: 38$ & $0: 03: 51$ & $0: 03: 49$ \\
\hline 105 & $0: 04: 47$ & $0: 03: 53$ & $0: 04: 05$ & $0: 04: 15$ \\
\hline 115 & $0: 05: 09$ & $0: 04: 57$ & $0: 05: 16$ & $0: 05: 07$ \\
\hline 125 & $0: 06: 37$ & $0: 05: 21$ & $0: 06: 23$ & $0: 06: 07$ \\
\hline 135 & $0: 06: 43$ & $0: 05: 37$ & $0: 06: 27$ & $0: 06: 16$ \\
\hline
\end{tabular}

The results of the table are then into graphs and displayed in Figure 10 .

\section{Email Transmission With Flooding Method}

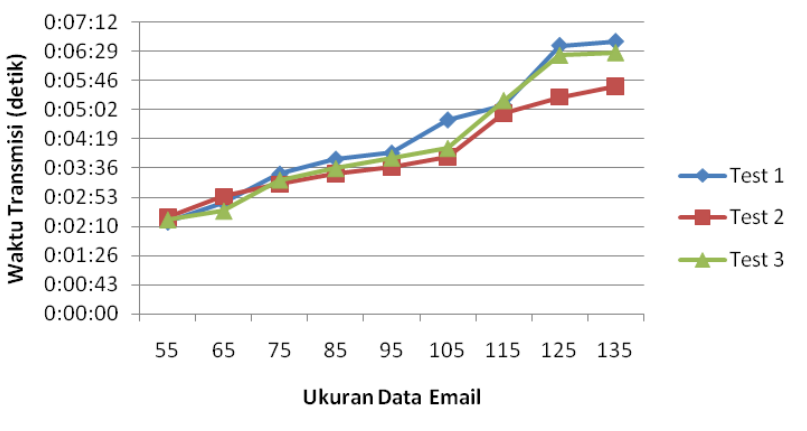

Figure 10: Graph of the size of e-mails against time

Based on the graph above, it can be seen that the different e-mail data sizes will get various transmission times. Testing is done in 3 times with different router speeds, approximatelly 20 to $25 \mathrm{~km} / \mathrm{h}$. Test results with flooding method show that the greater the size of the data sent, the greater of the time is needed for data transfer.

The method flooding can be applied to type network configurations Dynamic. If a node uses this method then the bundle- the mail that will be sent to the destination will be forwarded to broadcast to all the nodes it recognizes. So, every node that it recognizes must be able to accommodate data every time the transfer process. This must also be supported by adequate equipment in the data transfer process.

\section{Conclusion}

The internet network for email services can be implemented using a network with the Delay Tolerant Network (DTN) protocol in remote or remote areas, only by utilizing HSDPA cellular networks, and Wi-Fi points access networks, without requiring special infrastructure development and at a lower cost when compared to satellite communication services, The system has been able to capture and send e-mail using DTN network protocols.

Flooding Method with dynamic-type configuration, each bundlemail that will be sent to the destination with broadcast familiar to all nodes, so that each node that is recognized to be able to accommodate the data every time the transfer process, The data transfer process will be more reliable if supported by the selection of the right type and configuration of the wifi device. Thus, the range of $\mathrm{Wi}-\mathrm{Fi}$ devices in these remote areas can be adjusted to their geographical conditions. So that DTN-based email service networks can be applied to various regions that have different geographical conditions.

\section{References}

[1] F. E. Laumal, E. P. Hattu, and K. B. N. Nope, "Jurnal Rekayasa Elektrika.,” J. Rekayasa Elektr., vol. 13, no. 1, pp. 48-56, 2017.

[2] F. E. Laumal, K. B. N. Nope, and Y. S. Peli, "Earthquake Early Warning Management based on Client-Server using Primary Wave data from Vibrating Sensor,” J. Phys. Conf. Ser., vol. 953, no. 1, p. 12029, 2018.

[3] A. C. M. Jerejian, C. Reid, and C. S. Rees, "The contribution of email volume, email management strategies and propensity to worry in predicting email stress among academics," Comput. Human Behav., vol. 29, no. 3, pp. 991-996, 2013.

[4] W. Alge, "Email in the cloud: the challenges and benefits," Comput Fraud Secur., vol. 2012, no. 7, pp. 10-12, 2012.

[5] S. Uddin, K. Thompson, B. Schwendimann, and M. Piraveenan, "The impact of study load on the dynamics of longitudinal email communications among students," Comput. Educ., vol. 72, pp. 209-219, 2014.

[6] D. Sumecki, M. Chipulu, and U. Ojiako, "Email overload: Exploring the moderating role of the perception of email as a 'business critical' tool,” Int. J. Inf. Manage., vol. 31, no. 5, pp. 407-414, 2011. 
[7] K. Reinke and T. Chamorro-premuzic, "Computers in Human Behavior When email use gets out of control : Understanding the relationship between personality and email overload and their impact on burnout and work engagement," Comput. Human Behav., 2014.

[8] F. E. Laumal, "Jurnal Teknik Komputer Unikom - Komputika Volume 3, No .2 - 2014,” J. Tek. Komput. Unikom - Komputika, vol. 3, no. 2, pp. 23-28, 2014.

[9] S. Kominfo, "Pengguna Internet Di Indonesia 2016," 2016. [Online]. Available: http://statistik.kominfo.go.id/site/data?idtree $=424 \&$ iddoc $=1516$. [Accessed: 20-Mar-2017]," 2017.

[10] BIRO HUMAS and K. KOMINFO, "SIARAN PERS NO. 53/HM/KOMINFO/02/2018, Jumlah Pengguna Internet 2017 Meningkat, Kominfo Terus Lakukan Percepatan Pembangunan Broadband," 2018.

[11] K. Fall and S. Farrell, "DTN: an architectural retrospective," IEEE J. Sel. Areas Commun., vol. 26, no. 5, pp. 828-836, Jun. 2008.

[12] M. T. Scholar and R. Ujjaniya, "A Review on Delay Tolerant Network Security Routing Protocol," vol. 4, no. 3, pp. 580-583, 2018.

[13] E. Husni and A. Wibowo, "E-mail System for Delay Tolerant Network," no. 10

[14] S. D. Siswanti, "Pengembangan Sistem Aplikasi Pengiriman Data Daerah Terpencil Berbasis Delay Tolerant Network," J. GENERIC, vol. 8, no. 2, pp. 221-271, Sep. 2013.

[15] R. Suci, F. Jannatin, A. Suharsono, and A. Bhawiyuga, "Implementasi Publish-Subscribe Pada Delay Tolerant Network ( DTN )," vol. 1, no. 2, pp. 118-124, 2017.

[16] A. V. Singh, V. Juyal, and R. Saggar, "Trust-based Intelligent Routing Algorithm for Delay Tolerant Network using Artificial Neural Network," Wirel. Networks, vol. 23, no. 3, pp. 693-702, Apr. 2017.

[17] Y. Sobhan Babu and D. Kamesh, "Latency and Routing analysis in Throw box based DTN for challenged networks," Int. J. Adv. Trends Eng. Sci. Technol., vol. 26, no. 6, pp. 1-5, 2017.

[18] E. M. Husni and A. R. Sumarmo, "Designing a DTN-based Network for Delivering News Portal and Email Services to Remote Villages by Utilizing Train as a DTN Router," pp. 1-6.

[19] Y. HARRATI and A. ABDALI, "MaxHopCount: DTN congestion control algorithm under MaxProp routing," Int. J. Comput. Sci. Inf. Secur., vol. 17, no. 5, pp. 206-214, 2017.

[20] H. Wang, L. Song, G. Zhang, and H. Chen, "Timetable-aware opportunistic DTN routing for vehicular communications in battlefield environments," Futur. Gener. Comput. Syst., vol. 83, pp. 95 103,2018 